\title{
Wind Shear Target Echo Modeling and Simulation
}

\author{
Xiaoyang Liu, ${ }^{1,2}$ Chao Liu, ${ }^{1}$ and Wanping Liu' \\ ${ }^{1}$ School of Computer Science and Engineering, Chongqing University of Technology, Chongqing 400054, China \\ ${ }^{2}$ Postdoctoral Research Station of Information and Communication Engineering, Chongqing University, Chongqing 400030, China
}

Correspondence should be addressed to Xiaoyang Liu; 1xy3103@163.com

Received 3 December 2014; Revised 19 March 2015; Accepted 23 March 2015

Academic Editor: Filippo Cacace

Copyright (C) 2015 Xiaoyang Liu et al. This is an open access article distributed under the Creative Commons Attribution License, which permits unrestricted use, distribution, and reproduction in any medium, provided the original work is properly cited.

\begin{abstract}
Wind shear is a dangerous atmospheric phenomenon in aviation. Wind shear is defined as a sudden change of speed or direction of the wind. In order to analyze the influence of wind shear on the efficiency of the airplane, this paper proposes a mathematical model of point target rain echo and weather target signal echo based on Doppler effect. The wind field model is developed in this paper, and the antenna model is also studied by using Bessel function. The spectrum distribution of symmetric and asymmetric wind fields is researched by using the mathematical model proposed in this paper. The simulation results are in accordance with radial velocity component, and the simulation results also confirm the correctness of the established model of antenna.
\end{abstract}

\section{Introduction}

As for airborne weather radar, wind shear is a unique atmosphere phenomenon. Microburst is a main form in wind shear. Wind shear often refers to the wind speed or size changing suddenly. Wind shear especially low-level wind shear can cause the maximum damage to airplane. In the aeronautical meteorology, according to the structure of the wind field, wind shear can mainly consist of three kinds of basic situation: vertical wind shear of horizontal wind, horizontal wind shear of horizontal wind, and wind shear of vertical wind. In the actual atmosphere, these three kinds of wind shear can affect flight. According to the airplane relative to the wind vector, the wind shear can be divided into the following: wind shear, cross wind shear, partial wind shear, and head wind shear four forms [1-5].

The scale and strength of low-level wind shear are closely related to wind shear weather system and environmental conditions. Because the phenomenon of wind shear belongs to a small probability event, the existence time of this unique atmosphere phenomenon is only a few minutes [6-9]. It is not repeated. If we rely on the actual test method, not only the cost is very high, but also the risk is quite large, so it is necessary for us to study real wind shear weather change rule of the simulation method [10].

When people realize the serious harm of wind shear, people have invented many equipment which can detect wind field and wind shear, including ground anemometer theodolite, radiosonde wind profile, line radar laser radar, Doppler weather radar, Doppler sound radar, and airborne sensors. The malignant plane crash accident is mainly caused by wind shear [11]. Therefore, it is the most effective method for detecting low-level wind shear in time, so that the airplane has enough time and space to avoid it [12].

The testing technology of low-level wind shear is mainly by means of signal processing algorithm, analyzing radar echo signal of wind shear [13]. The echo power, wind speed of Doppler, and spectrum width parameters can be extracted by using signal processing algorithm. The wind speed of Doppler is the most important parameter among all the parameters, because it reflects the wind field characteristics of the movement [14-16].

The paper is organized as follows. Section 2 contains mathematical model of point target echo, and the signal model of target echo is established in Section 3. Wind field and antenna model are proposed in Section 4, followed by the analysis of simulation results in Section 5. Finally, Section 6 contains the conclusions.

\section{The Proposed Mathematical Model of Point Target Echo}

There is a relative motion between airborne weather radar and the meteorological scattering target. So the Doppler 
frequency shift consists of two parts: the speed of an airplane and meteorological scattering target. For airborne pulsed Doppler radar detecting meteorological target of wind shear, we assume that the speed of airplane is $V$, the average radial velocity among meteorological scattering target is $V_{r}$, the initial distance between the airplane and the meteorological scattering target is $r$, and the distance of airplane away from meteorological scattering unit is $r(t)$. The relationship between $r(t)$ and time $t$ is as follows:

$$
r(t)=r-V t-V_{r} t .
$$

The time rate of the phase $\gamma=-4 \pi r(t) / \lambda+\psi$ is

$$
\begin{aligned}
\frac{\mathrm{d} \gamma}{\mathrm{d} t} & =-\frac{4 \pi}{\lambda} \frac{\mathrm{d} r(t)}{\mathrm{d} t}=-\frac{4 \pi}{\lambda}\left(-V-V_{r}\right) \\
& =\frac{4 \pi}{\lambda} V+\frac{4 \pi}{\lambda} V_{r}=\omega_{c}+\omega_{R},
\end{aligned}
$$

where $\omega_{c}$ is the Doppler frequency shift caused by the airplane and $\omega_{R}$ is the Doppler frequency shift caused by the meteorological scattering target. Equation (2) indicates that the Doppler frequency shift $\omega_{R}$ can be extracted which is caused by the target movement of wind shear rain echo.

The average power of wind shear target rain echo can be expressed as

$$
P=\frac{P_{t} G^{2} \lambda^{2} \sigma}{(4 \pi)^{3} r^{4} L}
$$

where $P_{t}$ is the transmit power, $G$ is the antenna gain, $\lambda$ is the wavelength of airborne weather radar, the scattering rate of meteorological target is $\sigma$, system loss is $L$, and the distance between target and meteorological target is $r$.

We assume that the body reflectivity of meteorological target is $\eta ; V_{c}$ represents the target volume unit.

As for airborne weather radar, we assume that the target is the ideal point target; the effective scattering cross section of the target is $\sigma^{\prime}$. So

$$
P=\frac{P_{t} G^{2} \lambda^{2} \sigma^{\prime}}{(4 \pi)^{3} r^{4} L}=\frac{P_{t} G^{2} \lambda^{2} \eta V_{c}}{(4 \pi)^{3} r^{4} L},
$$

where the body reflectivity of meteorological target $\eta$ can be expressed as

$$
\eta=\frac{\pi^{5}}{\lambda^{4}}|K|^{2} D^{6}
$$

where $\lambda$ is the wavelength of airborne weather radar. $D$ represents the diameter of the target sphere, $|K|^{2}$ is the dielectric constant of scattering particle, and $z\left(z=D^{6}\right)$ denotes the reflection factor.

We assume that the radar transmitted signal is a narrow signal. It can be expressed as

$$
S(t)=\sqrt{2 P_{t}} u(t) e^{j 2 \pi f t}
$$

where

$$
u= \begin{cases}1, & 0 \leq u \leq 1 \\ 0, & \text { others }\end{cases}
$$

The $f$ is carrier frequency. So, echo signal can be regarded as a signal delay form of transmitted signal. Its amplitude is multiplied by a scale factor $K$.

We assume that the complex reflection constant is $\gamma$. We also defined the scale factor $K$ :

$$
K=\left[\frac{\lambda^{2}}{(4 \pi)^{3} R^{4} L}\right]^{1 / 2} G \gamma
$$

The echo signal of the mathematical formula can be expressed as

$$
S_{r}(t)=\sqrt{2 P_{t}} K S[t-\tau(t)]=K u[t-\tau(t)] e^{j 2 \pi f[t-\tau(t)]},
$$

where time delay $t$ can be expressed as

$$
\tau(t)=\frac{2 r(t)}{c+V} \approx \frac{2 r(t)}{c} ; \quad V \ll c .
$$

Putting (2) into (10), we can get

$$
\tau(t)=\frac{2 r}{c}-\frac{2 V}{c} t-\frac{2 V_{r}}{c} t
$$

Then by putting (11) into (9), we can get

$$
\begin{aligned}
S_{r}(t)= & \sqrt{2 P_{t}} K u\left[t-\frac{2 r}{c}+\frac{2 V}{c} t+\frac{2 V_{r}}{c} t\right] \\
& \cdot e^{j 2 \pi f\left[t-2 r / c+(2 V / c) t+\left(2 V_{r} / c\right) t\right]},
\end{aligned}
$$

where $2 r / c=\tau$ is time delay of target echo.

So, for a single wind shear meteorological target scattering body, echo signal of radar target can be expressed as

$V(t, r)$

$$
=A \exp \left[j 2 \pi f\left(t-\frac{2 r}{c}\right)+j \psi\right] u\left(t-\frac{2 r}{c}+\frac{2 V}{c} t+\frac{2 V_{r}}{c} t\right),
$$

where $2 r$ is the total path length and $\psi$ is the random phase caused by the scatter body. $A$ is the amplitude of echo signal. $A$ can be expressed as

$$
A=\sqrt{2 P}
$$

where $P$ denotes the average power of the wind shear rain echo.

\section{Signal Model of Target Echo}

We assume that $V_{i}$ denotes the speed component of target scatter body; $V_{a}$ represents the speed component of airplane along the radial. $\beta=2 \pi / \lambda$ is constant. We defined

$$
\Delta \omega=\omega_{i}+\omega_{a}=\beta\left(V_{i}-V_{a}\right)=\frac{2 \pi\left(V_{i}-V_{a}\right)}{\lambda} .
$$


The in-phase component $I$ and quadrature $Q$ component of the target echo signal can be expressed, respectively, as

$$
\begin{gathered}
I\left(n T_{s}\right)=\sum_{i=1}^{N} A_{i} \cos \left[\bar{\phi}_{i}+\beta\left(V_{i}-V_{a}\right) n T_{s}+\Delta \bar{\phi}\right]+\bar{n}\left(n T_{s}\right), \\
Q\left(n T_{s}\right)=\sum_{i=1}^{N} A_{i} \sin \left[\bar{\phi}_{i}+\beta\left(V_{i}-V_{a}\right) n T_{s}+\Delta \bar{\phi}\right]+\bar{n}\left(n T_{s}\right),
\end{gathered}
$$

where $\bar{\phi}_{i}$ is the random phase of the scatter target and $\Delta \bar{\phi}$ represents the transmitted phase error. $\bar{n}\left(n T_{s}\right)$ is the receiver noise. $n$ expresses the number of pulses. $T_{s}$ is the pulse time interval.

Signal amplitude $A_{i}$ can be obtained by radar equation and reflectivity factor. $A_{i}$ can be expressed as

$$
A_{i}=\sqrt{\mathrm{Rae} \cdot E_{t} \cdot \xi \cdot \mathrm{Vol}} \cdot G,
$$

where

$$
\text { Rae }=\frac{P_{t} \cdot \lambda^{2}}{(4 \cdot \pi)^{3} \cdot R^{4} \cdot R \_ \text {loss }},
$$

where Rae is the constant of radar equation and $R$ loss represents the receiver loss. Vol indicates the volume of the scatter body. $\xi$ shows the multipath fading factor. $G$ is the antenna gain. $E_{t}$ is wind shear wind field reflectivity.

Signal phase is mainly decided by the Doppler frequency shift. Doppler frequency shift consists of two parts, $\omega_{i}$ and $\omega_{a}$.

The total rain echo signal phase can be expressed as

$$
\psi=\overline{\phi_{i}}+\beta\left(V_{i}-V_{a}\right)+\Delta \bar{\phi} .
$$

The principle diagram of wind shear target echo simulation is shown in Figure 1.

\section{Wind Field and Antenna Model}

4.1. Wind Field Model of Wind Shear. In order to simulate the whole space wind field within the scope of the $x-y-z$ three direction of the wind speed, we build a microburst wind shear of wind field model, and the simulation process is as follows:

(1) The speed of the vertical flow

(a) The calculation of the radial distance

$$
\mathrm{RC}=\sqrt{(X-X C)^{2}+(Y-Y C)^{2}},
$$

where $X$ and $Y$ are the airplane's $x$ and $y$ position coordinates and $X C$ and $Y C$ are the center of wind field in $x$ and $y$ position. $\mathrm{RC}$ is the radial distance of airplane. The minimum value of RC is set to 2.0 .

(b) We define a parameter RA; RA is related to the position of airplane, wind shear, and distortion factor

$$
\mathrm{RA}=\mathrm{RT}+\sqrt{\mathrm{RT}^{2}+R^{2} \cdot\left(1-\mathrm{GR}^{2}\right)},
$$

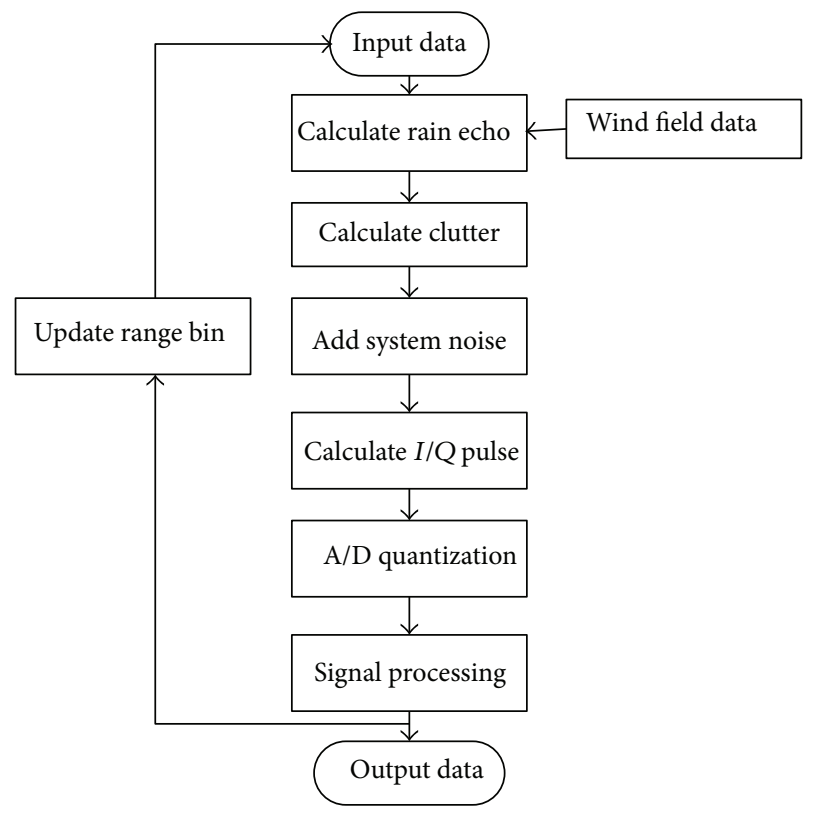

FIgURE 1: The principle diagram of wind shear target echo simulation.

where

$$
\begin{gathered}
\mathrm{RT}=R \cdot \mathrm{COSA} \cdot \mathrm{GR} \\
\mathrm{COSA}=\frac{X-X C}{\mathrm{RC}} \cdot \frac{\mathrm{GX}}{\mathrm{GR}}+\frac{Y-Y C}{\mathrm{RC}} \cdot \frac{\mathrm{GY}}{\mathrm{GR}}, \\
\mathrm{GR}=\sqrt{\mathrm{GX}^{2}+\mathrm{GY}^{2}}
\end{gathered}
$$

where GX and GY are the distortion factors in $x$ and $y$ position. The minimum value of GR is set to 0.002 . The minimum value of RA is set to 2.0 .

(2) The radial velocity of horizontal flow

The variable of radial velocity distribution is defined by VRR:

$\mathrm{VRR}=0 ; \quad H \geq \mathrm{HT}$,

$\mathrm{VRR}=0.75 \cdot \mathrm{GVZ} \cdot \mathrm{VZO} \cdot \frac{\mathrm{RA}}{\mathrm{HT}^{2}} \cdot(\mathrm{HT}-H) ; \quad$ others,

where $H$ is the height of airplane, VZO is the initial reference velocity, HT is the height limit of horizontal airflow, and GVZ is the gain factor of wind field.

(3) The wind shear model

According to the changing rule of the horizontal wind $w_{x}$ and vertical wind $w_{y}$, the following wind shear model is established:

$$
\begin{gathered}
w_{x}=A \sin \left(\omega_{0} t+\varphi_{0}\right), \\
w_{y}=B\left[1-\cos \left(\omega_{0} t+\varphi_{0}\right)\right] .
\end{gathered}
$$




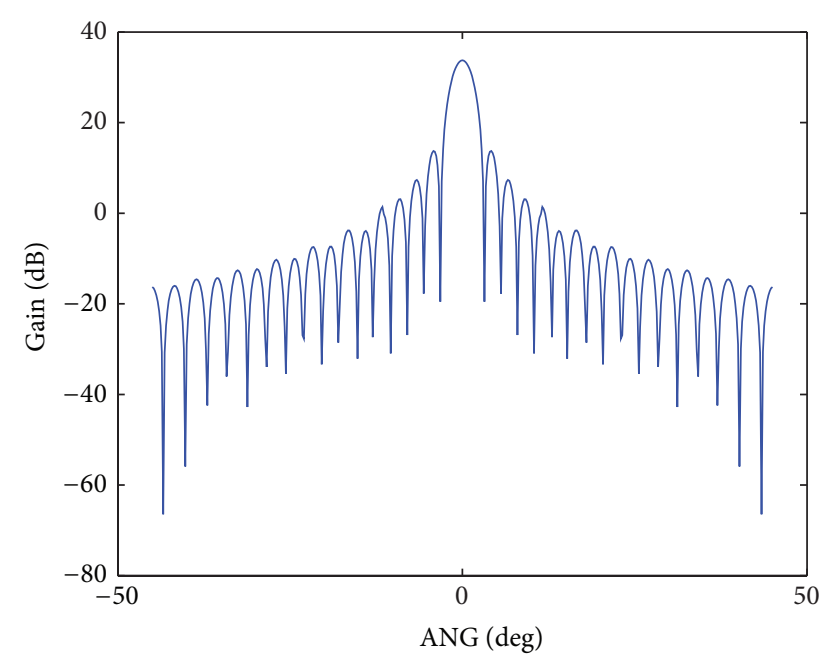

FIgURE 2: The pattern of antenna beam.

TABLE 1: The parameters settings of simulation.

\begin{tabular}{lcc}
\hline Variable & Value & Unit \\
\hline Pulse repetition frequency & 3500 & $\mathrm{~Hz}$ \\
Pulse width & 1.5 & $\mathrm{us}$ \\
Sampling interval & 1 & $\mathrm{us}$ \\
Operating frequency & 9.0 & $\mathrm{GHz}$ \\
Range resolution & 150 & $\mathrm{~m}$ \\
Antenna gain & 34 & $\mathrm{~dB}$ \\
Antenna beamwidth & 2.8 & $\mathrm{~dB}$ \\
System noise & 2.5 & $\mathrm{~dB}$ \\
Transmitter power & 200 & $\mathrm{~W}$ \\
\hline
\end{tabular}

In the formula, $A$ and $B$ denote the size of horizontal wind and vertical wind, respectively. $\omega_{0}=2 \pi / t_{0}$. $t_{0}$ shows the total time of the plane through the microburst. $\varphi_{0}$ expresses the initial phase. To solve the derivative $t_{0}$, we also can get

$$
\begin{aligned}
& \dot{w}_{x}=A \omega_{0} \cos \left(\omega_{0} t\right), \\
& \dot{w}_{y}=B \omega_{0} \sin \left(\omega_{0} t\right) .
\end{aligned}
$$

4.2. Antenna Model. The antenna model is made by Bessel function. The gain of main lobe is $34.2 \mathrm{~dB}$. The $3 \mathrm{~dB}$ beam width is $2.8^{\circ}$ and the center of first side lobe is $4.4^{\circ}$ and the antenna beam pattern is shown in Figure 2.

\section{Simulation Results Analysis}

5.1. The Main Parameters Settings. The main simulation parameter settings are shown in Table 1.

\subsection{The Simulation Performance Analysis and Discussion}

5.2.1. The Condition of No Wind Shear. The wind speed is set to 0 , and the reflectivity is set to $0 \mathrm{dBZ}$, get rid of the plane, the airplane of the speed along the antenna beam radial velocity

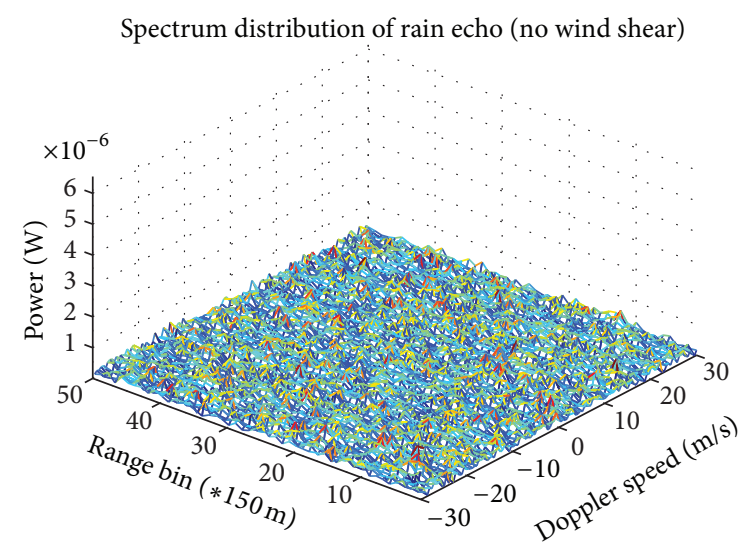

FIGURE 3: Rain Echo Spectrum Distribution of no Wind Shear.

Spectrum distribution of rain echo (the first scan line)

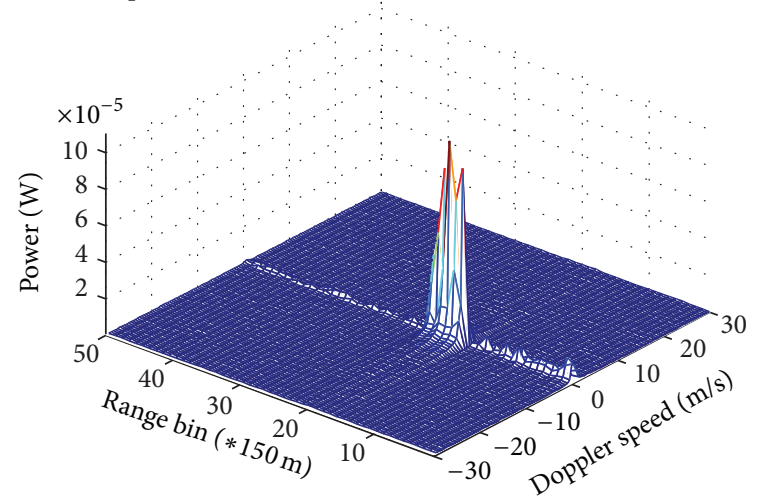

Figure 4: Rain Echo Spectrum Distribution of the first scan line (three-dimensional diagram).

takes 0 . The speed of Doppler frequency is 0 , because there is no the signal of wind shear. The signal of radar received will exist noise and only considers clutter, which is showed in Figure 3.

5.2.2. The Simulation of Symmetric Wind Field. Considering symmetry wind field, the reflectivity is set to $30 \mathrm{dBZ}$, because the intensity of rain echo is related to the intensity of the wind field. The center of wind field is large according to the data of wind field model of microburst wind shear, and the intensity of rain echo is large; by contrast wind field edge rain echo is weak, as is shown in Figures 4 and 5. Figures 4 and 5 depict the spectrum distribution of rain echo and range bin change in the first scan line. Figures 6 and 7 depict the spectrum distribution of rain echo and range bin change in the thirtieth scan line.

As can be seen from Figures 4 and 5. the wind speed is almost perpendicular to the radial in microburst wind field edge. The radial velocity component is almost equal to 0 . It means that it almost does not produce Doppler frequency shift, and as shown in Figures 6 and 7 it shows that the thirtieth scan line is in the position of the wind field center, so 


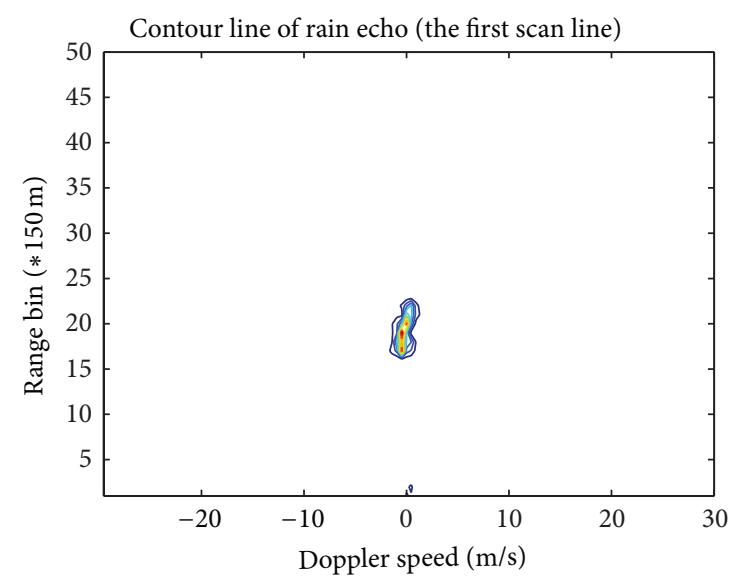

Figure 5: Rain Echo Spectrum Distribution of the first scan line (Contour Map).

Spectrum distribution of rain echo ( the thirtieth scan line)

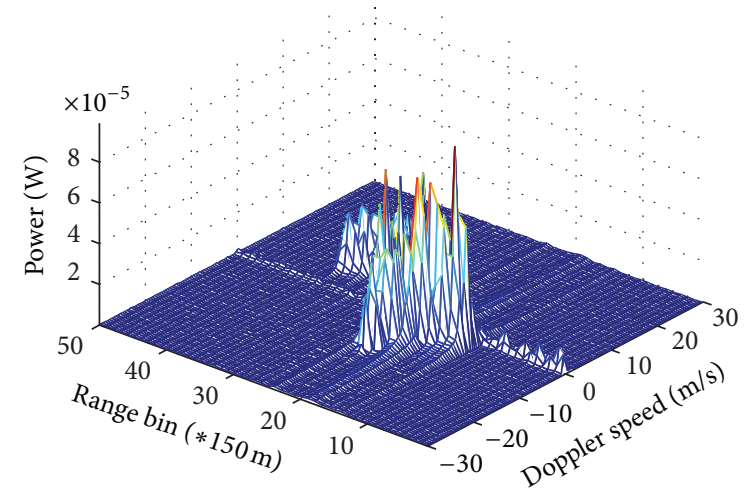

FIgURE 6: Rain Echo Spectrum Distribution of the thirtieth scan line (three-dimensional diagram).

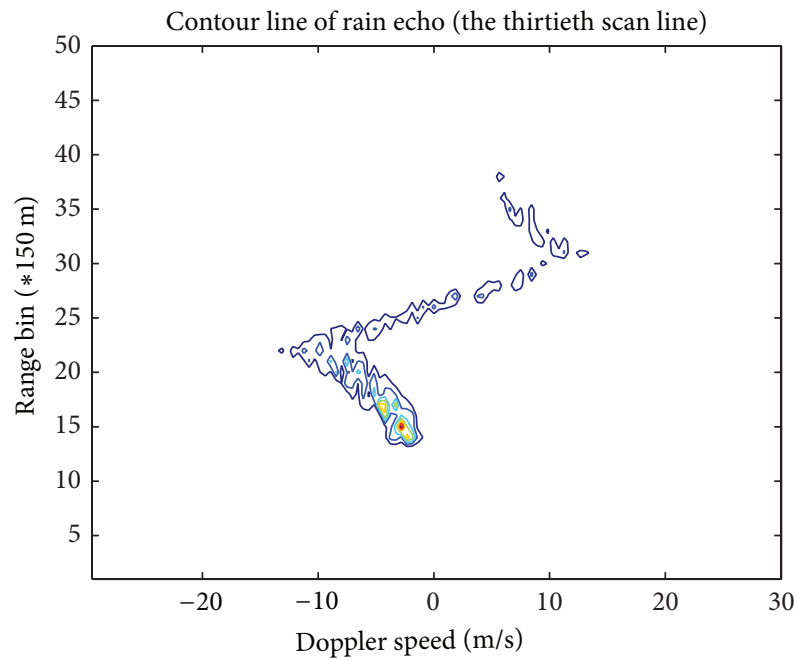

FIgURE 7: Rain Echo Spectrum Distribution of the thirtieth scan line (Contour Map).

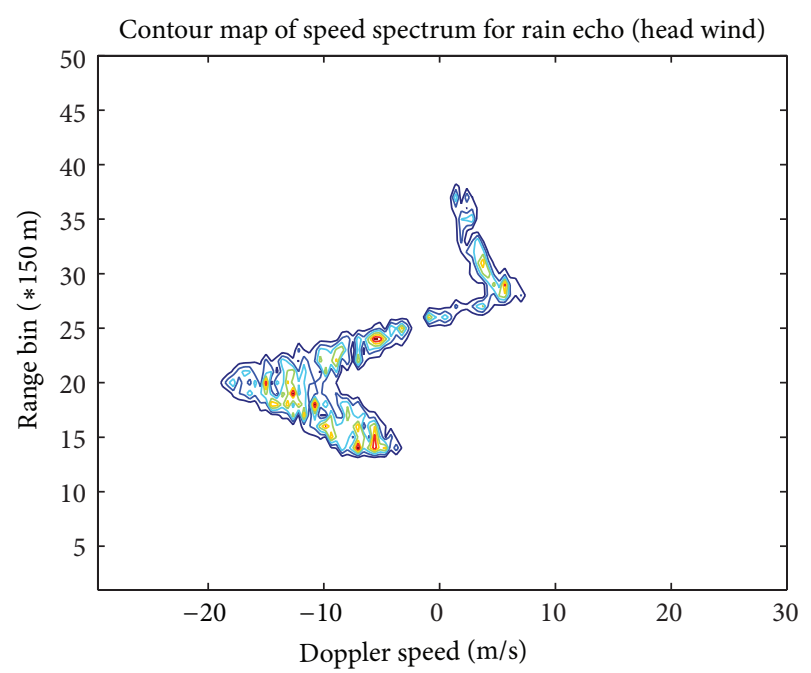

FIgURE 8: Rain Echo Spectrum Distribution of asymmetric wind field for head wind (Contour Map).

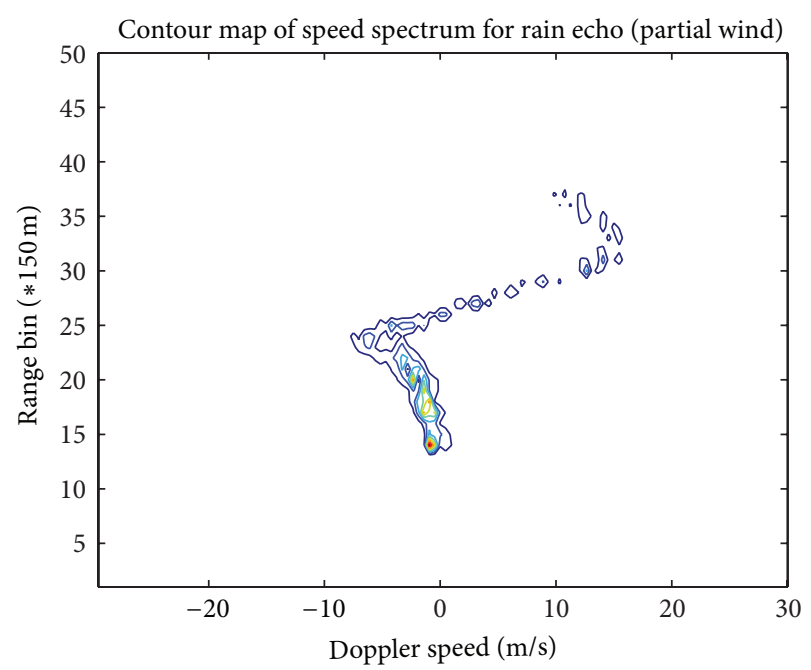

FIGURE 9: Rain Echo Spectrum Distribution of asymmetric wind field for partial wind (Contour Map).

relative to the first scan line, the signal strength of rain echo is greater, and the radial velocity component is obvious.

5.2.3. The Simulation of Asymmetric Wind Field. Considering asymmetry wind field, we assume that the reflectivity is $30 \mathrm{dBZ}$. The settings of other parameters are showed in Table 1. Figure 8 depicts the spectrum distribution under the head hind, while Figure 9 depicts the spectrum distribution under the partial hind.

Figures 8 and 9 show that the spectrum profile is related to rain echo signal and range bin under the head wind and partial wind in the thirtieth scan line. As can be seen from Figures 8 and 9 , the simulation results can reflect the actual rain echo distribution. 


\section{Conclusion}

In this paper, a novel mathematical model of wind field in wind shear is established. The mathematical model of rain echo point target echo and antenna model are proposed. The Rain Echo Spectrum Distribution under different scan lines is studied in this paper. The simulation realized the symmetric wind field and asymmetric wind field, in a given antenna model and system parameters. It is explained that the data in different coordinate systems can be transformed and an example having analytical solution is given.

The simulation results show that the wind field data of the established model can reflect the basic characteristics of the wind shear in perfect. The distribution of speed spectrum of rain target echo signal can reflect the wind shear condition. The simulation results are in accordance with radial velocity component.

\section{Conflict of Interests}

The authors declare that there is no conflict of interests regarding the publication of this paper.

\section{Acknowledgment}

The paper is supported by Chongqing Science and Technology Committee Fund of Foundation and Cutting-edge Research Plan (cstc2014jcyjA40007).

\section{References}

[1] C. Liu, T. Li, J.-T. Mei, and Y.-F. Cheng, "Three-dimensional modeling and simulation of microburst," Computer Simulation, vol. 28, no. 12, pp. 47-52, 2011.

[2] X.-R. Zhang, Y. Li, T. Li, and Y.-F. Cheng, "Simulation method of airborne forward-looking windshear radar echo signals," Journal of System Simulation, vol. 21, no. 22, pp. 7023-7025, 2009.

[3] M. S. Mason, G. S. Wood, and D. F. Fletcher, "Numerical simulation of downburst winds," Journal of Wind Engineering and Industrial Aerodynamics, vol. 97, no. 11-12, pp. 523-539, 2009.

[4] M. T. Chay, F. Albermani, and R. Wilson, "Numerical and analytical simulation of downburst wind loads," Engineering Structures, vol. 28, no. 2, pp. 240-254, 2006.

[5] S. H. Pourtakdoust, M. Kiani, and A. Hassanpour, "Optimal trajectory planning for flight through microburst wind shears," Aerospace Science and Technology, vol. 15, no. 7, pp. 567-576, 2011.

[6] E. Firtin, Ö. Güler, and S. A. Akdaĝ, "Investigation of wind shear coefficients and their effect on electrical energy generation," Applied Energy, vol. 88, no. 11, pp. 4097-4105, 2011.

[7] J.-J. Gonzalez, P. Freton, F. Reichert, and D. Randrianarivao, "Turbulence and magnetic field calculations in high-voltage circuit breakers," IEEE Transactions on Plasma Science, vol. 40, no. 3, pp. 936-945, 2012.

[8] E. B. Muhando, T. Senjyu, H. Kinjo, and T. Funabashi, "Extending the modeling framework for wind generation systems: RLSbased paradigm for performance under high turbulence inflow," IEEE Transactions on Energy Conversion, vol. 24, no. 1, pp. 211221, 2009.
[9] C. J. Matyas, "Use of ground-based radar for climate-scale studies of weather and rainfall," Geography Compass, vol. 4, no. 9, pp. 1218-1237, 2010.

[10] P. B. Chilson and M. B. Yeary, "Hands-on learning modules for interdisciplinary environments: an example with a focus on weather radar applications," IEEE Transactions on Education, vol. 55, no. 2, pp. 238-247, 2012.

[11] H. Kim, C. Singh, and A. Sprintson, "Simulation and estimation of reliability in a wind farm considering the wake effect," IEEE Transactions on Sustainable Energy, vol. 3, no. 2, pp. 274-282, 2012.

[12] G. F. da Silva, J. C. Marín, and A. Barroso, "Evaluation of shear flow in composite wind turbine blades," Composite Structures, vol. 93, no. 7, pp. 1832-1841, 2011.

[13] C. Yue and S. Shou, "Responses of precipitation to vertical wind shear, radiation, and ice clouds during the landfall of Typhoon Krosa (2007)," Atmospheric Research, vol. 99, no. 2, pp. 344-352, 2011.

[14] M. Elamouri, F. Ben Amar, and A. Trabelsi, "Vertical characterization of the wind mode and its effect on the wind farm profitability of Sidi Daoud-Tunisia," Energy Conversion and Management, vol. 52, no. 2, pp. 1539-1549, 2011.

[15] F. S. Marzano, S. Mori, J. A. Weinman, and M. Montopoli, "Modeling polarimetric response of spaceborne synthetic aperture radar due to precipitating clouds from $\mathrm{x}$ - to ka-band," IEEE Transactions on Geoscience and Remote Sensing, vol. 50, no. 3, pp. 687-702, 2012.

[16] T. Jian, Y. He, F. Su, D. Ping, and X. Gu, "Fast converging estimator for covariance matrix structure of compound-gaussian clutter," Chinese Journal of Electronics, vol. 19, no. 3, pp. 579-582, 2010. 


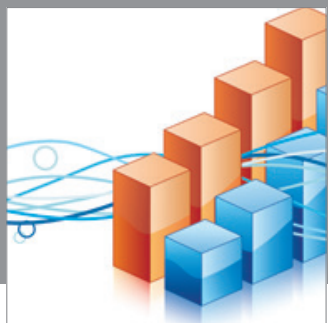

Advances in

Operations Research

mansans

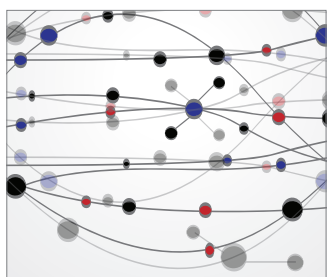

The Scientific World Journal
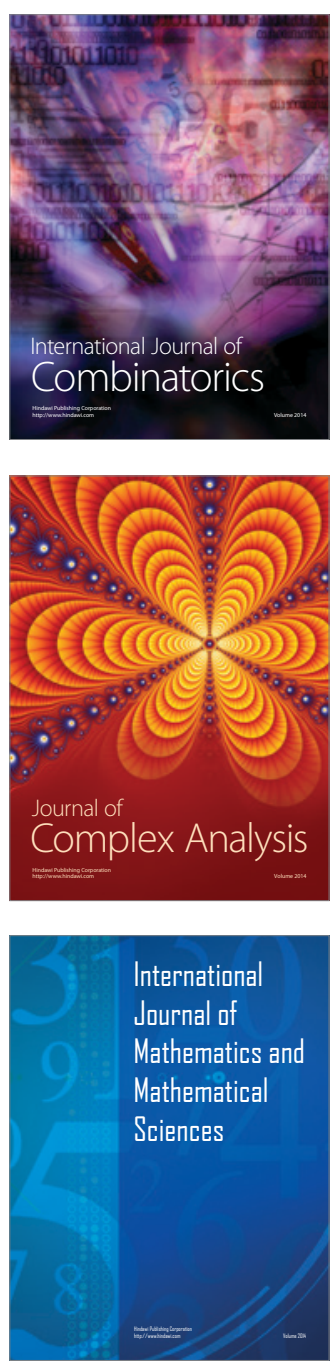
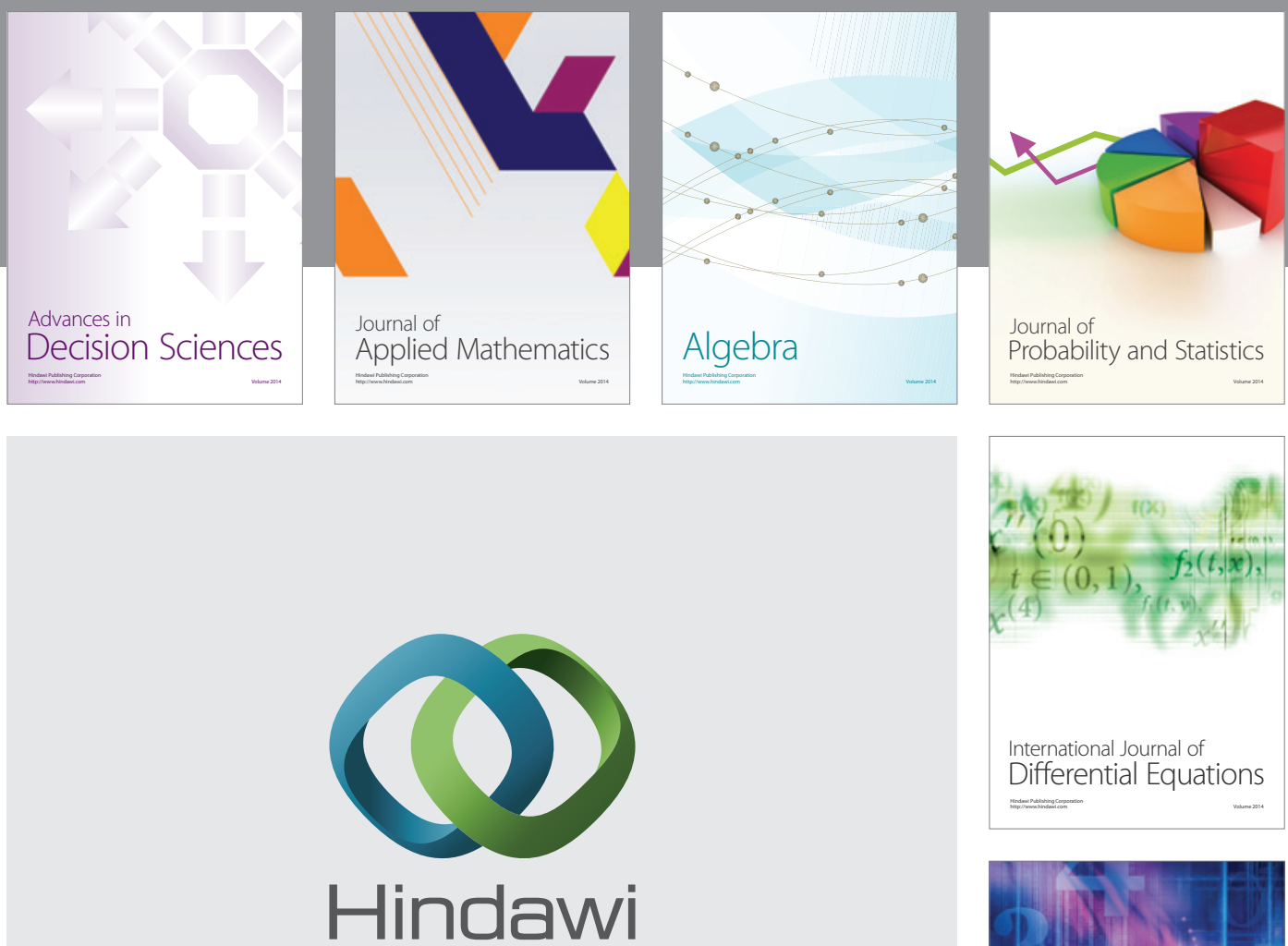

Submit your manuscripts at http://www.hindawi.com
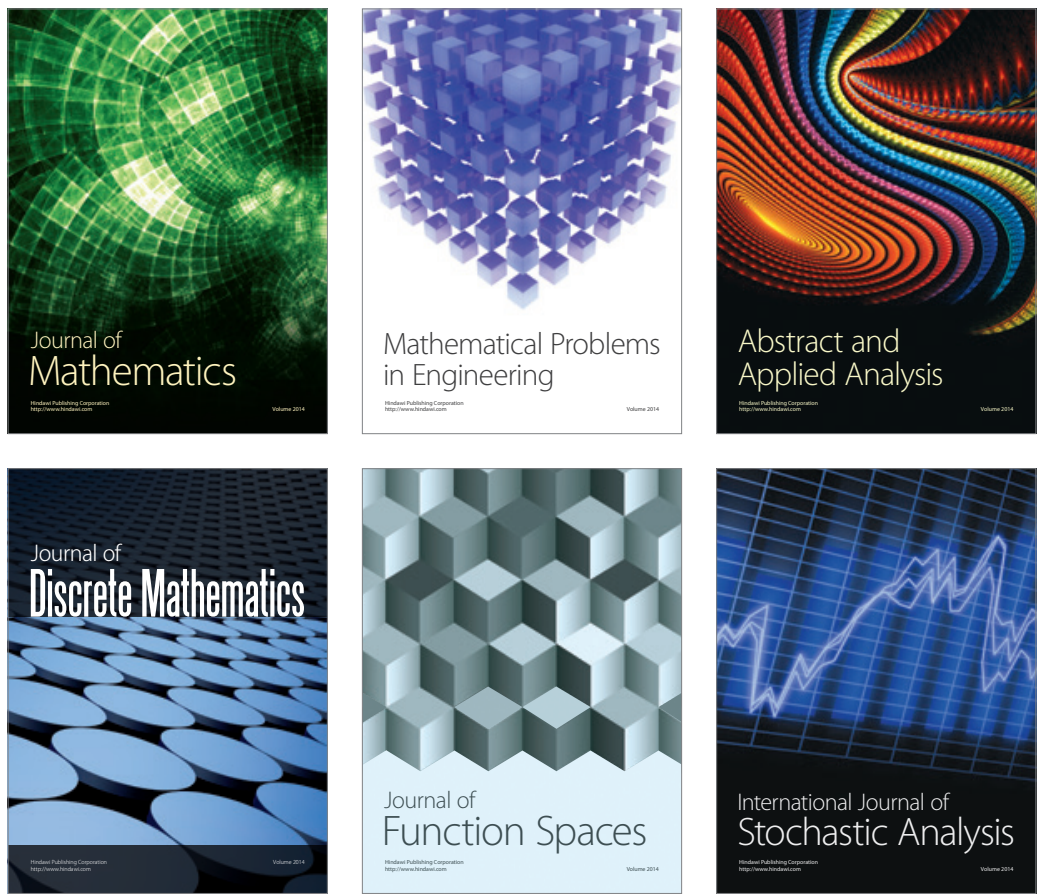

Journal of

Function Spaces

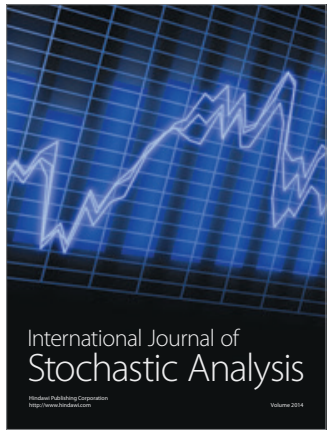

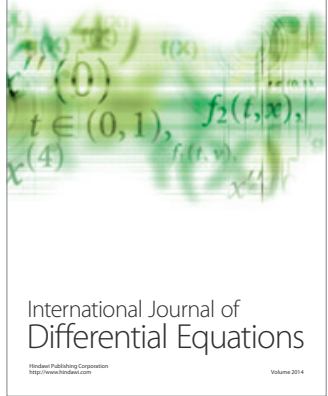
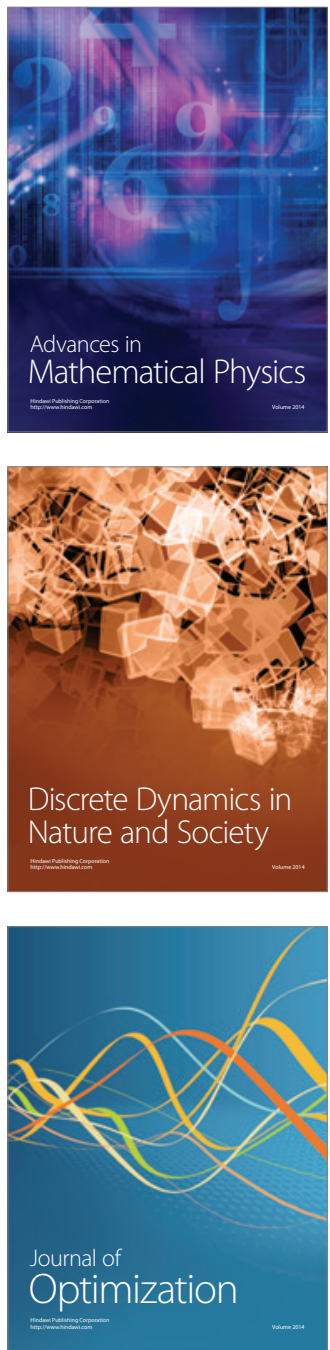